\title{
Respiratory health among office workers in Malaysia and endotoxin and $(1,3)-\beta$ - glucanin office dust
}

\begin{abstract}
Objective: To examine the associations between endotoxin and (1,3)- $\beta$-glucan concentrations in office dust and respiratory symptoms and airway inflammation among 695 office workers in Malaysia. Methods: Health data were collected using a questionnaire, sensitisation testing and measurement of fractional exhaled nitric oxide (FeNO). Indoor temperature, relative air humidity (RH) and carbon dioxide (CO 2) were measured in the offices and settled dust was vacuumed and analysed for endotoxin and (1,3)- $\beta$-glucan concentrations. Associations were analysed by two level multiple logistic regression. Results: Overall, $9.6 \%$ of the workers had doctor-diagnosed asthma, $15.5 \%$ had wheeze, $18.4 \%$ had daytime attacks of breathlessness and $25.8 \%$ had elevated FeNO ( $\geq 25 \mathrm{ppb}$ ). The median levels in office dust were 11.3 EU/mg endotoxin and $62.9 \mathrm{ng} / \mathrm{g}(1,3)-\beta$-glucan. After adjusting for personal and home environment factors, endotoxin concentration in dust was associated with wheeze $(\mathrm{P}=0.02)$ and rhino conjunctivitis $(P=0.007)$. The amount of surface dust $(P=0.04)$ and $(1,3)-\beta$ glucan concentration dust $(\mathrm{P}=0.03)$ were associated with elevated FeNO. Conclusion: Endotoxin in office dust could be a risk factor for wheeze and rhino conjunctivitis among office workers in mechanically ventilated offices in a tropical country. The amount of dust and $(1,3)-\beta$-glucan (a marker of indoor mould exposure) were associated with Th2 driven airway inflammation.
\end{abstract}

Keyword: Asthma; Fractional exhaled nitric oxide; Microbial; Rhinoconjunctivitis;Tropical 